\title{
Medication in older patients reviewed multiple ways (MORE) study
}

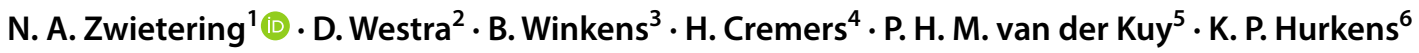

Received: 22 November 2018 / Accepted: 4 July 2019 / Published online: 13 July 2019

(c) The Author(s) 2019

\begin{abstract}
Background Polypharmacy in older patients can lead to potentially inappropriate prescribing. The risk of the latter calls for effective medication review to ensure proper medication usage and safety. Objective Provide insight on the similarities and differences of medication review done in multiple ways that may lead to future possibilities to optimize medication review. Setting This study was conducted in Zuyderland Medical Centre, the second largest teaching hospital in the Netherlands. Method This descriptive study compares the quantity and content of remarks identified by medication review performed by a geriatrician, outpatient pharmacist, and Clinical Decision Support System. The content of remarks is categorized in seven categories of possible pharmacotherapeutic problems: 'indication without medication', 'medication without indication', 'contra-indication/interaction/side-effect', 'dosage problem', 'double medication', 'incorrect medication' and 'therapeutic drug monitoring'. Main outcome measure Number and content of remarks on medication review. Results The Clinical Decision Support System $(1.8 \pm 0.8$ vs. $0.9 \pm 0.9, p<0.001)$ and outpatient pharmacist $(1.8 \pm 0.8$ vs. $0.9 \pm 0.9, p=0.045)$ both noted remarks in significantly more categories than the geriatricians. The Clinical Decision Support System provided more remarks on 'double medication', 'dosage problem' and 'contraindication/interaction/side effects' than the geriatrician $(p<0.050)$, while the geriatrician did on 'medication without indication' $(p<0.001)$. The Clinical Decision Support System noted significantly more remarks on 'contraindication/interaction/side effects' and 'therapeutic drug monitoring' than the outpatient pharmacist, whereas the outpatient pharmacist reported more on 'indication without medication' and 'medication without indication' than the Clinical Decision Support System $(p \leq 0.007)$. Conclusion Medication review performed by a geriatrician, outpatient pharmacist, and Clinical Decision Support System provides different insights and should be combined to create a more comprehensive report on medication profiles.
\end{abstract}

Keywords Clinical Decision Support System $\cdot$ Elderly $\cdot$ Medication review $\cdot$ Netherlands $\cdot$ Potentially inappropriate prescribing

N. A. Zwietering

anne.zwietering@mumc.nl

1 Department of Internal Medicine, Geriatric Medicine, Maastricht University Medical Centre, Maastricht University, PO Box 5800, 6202 AZ Maastricht, The Netherlands

2 Department of Health Services Research, Care and Public Health Research Institute (CAPHRI), Maastricht University, Maastricht, The Netherlands

3 Department of Methodology and Statistics, Care and Public Health Research Institute (CAPHRI), Maastricht University, Maastricht, The Netherlands
4 Department of Clinical Pharmacy, Pharmacology and Toxicology, Zuyderland Medical Centre, Sittard-Geleen, The Netherlands

5 Department of Hospital Pharmacy, Erasmus Medical Centre, Rotterdam, The Netherlands

6 Department of Internal Medicine, Geriatric Medicine, Zuyderland Medical Centre, Sittard-Geleen, The Netherlands 


\section{Impacts on practice}

- The Clinical Decision Support System is particularly potent in indicating 'contraindications/interactions/side effects' and can help reduce potentially inappropriate prescribing.

- Combined medication review by a geriatrician, an outpatient pharmacist, and a Clinical Decision Support System has different perspectives and should be combined to ensure adequate medication usage and safety. Moreover it could potentially reduce (increasing) health care costs.

- Benzodiazepines, betahistin, opiates, antihistamines, antihypertensive agents and non-steroidal-anti-inflammatory drugs provide for the majority of drug related problems in the Dutch hospital setting.

\section{Introduction}

As the general population ages, the number of older patients $(\geq 65$ years) in hospitals increases [1-5]. These (ill) older patients make for a vulnerable group. This vulnerability is caused by factors such as reduced selfreliance due to multimorbidity, reduced cognitive skills, malnutrition, and physical constraints [6-8]. Because of their multimorbidity, polypharmacy ( $\geq 5$ medicines) is common in this group. Besides their intended effects, these medicines have potential risks and adverse effects. The likelihood of the latter is significantly increased in older patients due to their vulnerability and altered pharmacokinetics and dynamics [9]. Prescribing medication in older patients is therefore complex and poses challenges.

The risk of potentially inappropriate prescribing (PIP) calls for effective methods to ensure adequate medication usage and safety. One of these methods is proper collaboration and coordination between patient or caregiver, physicians, pharmacists and other healthcare professionals. However, involvement of different physicians can cause a variety of medication prescriptions, increasing the risk of interactions and adverse effects if this is not taken into account whilst prescribing [10]. Geriatricians care for nearly the full spectrum of diseases seen in general medicine, taking into account the complexities in geriatric medicine. Therefore they often perform medication review: a structured evaluation of a patient's medicines with the aim of optimising medicines use and improving health outcomes [11].

In the Netherlands medication review is mainly performed by geriatricians, pharmacists and general practitioners, using the STRIP (Systematic Tool to Reduce Inappropriate Prescribing) method. The national guideline focuses on analysing potential pharmacotherapeutic problems, including: undertreatment, ineffective medication, overtreatment, (potential) adverse effects, contraindication, interaction and dosage problem [12]. The STOPP/ START (Screening Tool of Older Persons' potentially inappropriate Prescriptions/Screening Tool to Alert Doctors to the Right Treatment) criteria $[13,14]$ are part of this analysis. The STOPP criteria describe PIP in older patients, whereas the START criteria provide guidance in prescribing medication in order to avoid undertreatment.

Although periodic medication review can lead to prevention of PIP $[15,16]$, there is no consensus on what such a review should comprise. In recent years, it has become apparent that Clinical Decision Support Systems (CDSSs) can provide support in medication reviews and could possibly reduce medication-related errors [17-19]. CDSSs could therefore contribute in improving quality of care and outcomes in older patients.

Moreover, pharmacists have extensive knowledge on pharmacokinetics and dynamics and could provide valuable insights in performing medication review. Hence, incorporating pharmacists in the process of medication review could improve prescribing appropriateness [20, 21].

\section{Aim of the study}

In this observational study, the similarities and differences of medication reviews performed by a geriatrician, an outpatient pharmacist, and the hospital's CDSS are described. We compare the quantity and types of possible pharmacotherapeutic problems identified by these three different perspectives. A better understanding of these perspectives could lead to possible optimization of medication review.

\section{Ethics approval}

The study was approved by the Zuyderland Medical Ethical Testing Committee (METC) (study 16-N-115) and obtaining informed consent was waived.

\section{Method}

\section{Setting}

This study was conducted in Zuyderland Medical Centre, a large teaching hospital in the Netherlands that treats roughly 190,000 patients per year. The hospital is located in one of 
the fastest aging regions [22], hence many older patients are treated.

\section{Clinical rule reporter (CRR)}

The CRR is a CDSS that is developed in the Zuyderland Medical Centre. It currently reviews medication profiles of all hospitalized patients. In addition, data on medication profiles of specific outpatient populations can be imported and reviewed. The system has access to all medication prescriptions of the past few months, through a digital network of regional pharmacies. Additionally, it has access to patient characteristics such as age, gender, co-medication and laboratory values. There is no digital link between the CRR and general practitioner data or medical history. The CRR combines information to obtain specific advice based on clinical rules (i.e. algorithms). These are clearly defined rules, that include the latest version of the STOPP/START criteria $[13,14]$ and utilize triggers to identify the need to discontinue or add medication, or aim for dose-reduction. During this study, 293 rules were operational, which is on top of medication surveillance for high-risk medication. The CRR reports by means of 'green' (no additional action needed) or 'red' (definite action needed) alerts. This implies the CRR checks for certain conditions by means of clinical rules and if this condition is met, a 'green' alert is noted [e.g. the use of proton pump inhibitors (PPIs) when using acetylsalicylic acid (ASA) at elder age]. On the other hand, hazardous combinations or an increased risk of adverse events, will generate a 'red' alert (e.g. the use of metformin in renal failure). Both 'green' and 'red' alerts are considered relevant because medication review by a physician or pharmacist should also comprise these checks. The clinical rules are updated based on insights from professional networks, research and guidelines.

\section{Data collection and analysis}

Between May and July 2016, all new patients to the geriatric outpatient clinic were included $(n=200)$. There were no specific in- or exclusion criteria. Patient characteristics (i.e. gender, age, number of medications, and medication categorized to ATC (Anatomical Therapeutic Chemical Classification System) code [23]) were extracted from the electronic patient file and medication system. Based on the information available in the patient's file, one of seven geriatricians performed a medication review $(n=200)$ on the day of visit using the national guideline [12]. The geriatricians were unaware of the study as medication review is considered part of the standard comprehensive geriatric assessment (CGA). The remarks on medication review were retrieved from the patient's file by the research team. Furthermore, an outpatient pharmacist reviewed the patient's medication independently in a consultation prior to the appointment at the geriatrician while having access to the same information as the geriatricians. These reviews were also guided by the previously mentioned national guideline. The remarks on medication review by the pharmacist were sent to the research team. Due to logistical challenges, 54 out of 200 medication profiles were reviewed by the pharmacist. These patients were selected randomly, based on presence of the pharmacist that day. Finally, 197 out of 200 medication profiles were assessed by the CDSS ( 3 patients did not consent to the digital exchange of data on medication use).

The remarks of the geriatrician, outpatient pharmacist and reports from the CDSS were categorized by the research team in seven pre-established categories (Table 1) that were used in previous research [24] and are based on possible pharmacotherapeutic problems [12]. Next, the quantity and content of remarks in these categories was compared. Moreover, the pharmacist focused on efficiency of medication prescriptions, drug adherence, use of over-the-counter (OTC) medications, and presence of a medication organizer or blister pack in addition to the seven categories. Drug adherence was assessed based on questions to patient or caregiver whether medication was used as prescribed and if

Table 1 Overview of remarks per patient by the geriatrician, outpatient pharmacist and CDSS

\begin{tabular}{llll}
\hline & $\begin{array}{l}\text { Geriatrician } \\
(\mathrm{n}=200)\end{array}$ & $\begin{array}{l}\text { Outpatient } \\
\text { pharmacist } \\
(\mathrm{n}=54)\end{array}$ & $\begin{array}{l}\text { CDSS } \\
(\mathrm{n}=197)\end{array}$ \\
\hline $\begin{array}{l}\text { Total number of remarks } \\
\text { Characteristic (mean } \pm \mathrm{SD})\end{array}$ & 263 & 145 & 945 \\
$\quad \begin{array}{l}\text { Number of remarks } \\
\text { Number of different cat- }\end{array}$ & $1.3 \pm 1.5$ & $2.7 \pm 1.4$ & $4.6 \pm 3.6^{\mathrm{b}}$ \\
$\quad$ egories & & $1.8 \pm 0.8^{\mathrm{a}}$ & $1.8 \pm 0.8^{\mathrm{b}}$ \\
$\begin{array}{l}\text { Categories (mean } \pm \text { SD) } \\
\text { Indication without medica- }\end{array}$ & $0.9 \pm 1.0$ & $1.3 \pm 1.0^{\mathrm{ac}}$ & $0.7 \pm 1.0$ \\
$\quad$ tion & & & \\
$\quad \begin{array}{l}\text { Medication without indica- } \\
\text { tion }\end{array}$ & $0.1 \pm 0.6^{\mathrm{b}}$ & $0.6 \pm 0.8^{\mathrm{ac}}$ & $0.0 \pm 0.0$ \\
$\quad$ Contra-indication/interac- & $0.0 \pm 0.2$ & $0.3 \pm 0.5^{\mathrm{a}}$ & $3.5 \pm 2.7^{\mathrm{bc}}$ \\
$\quad$ tion/adverse effect & & & \\
$\begin{array}{l}\text { Dosage problem } \\
\text { Double medication }\end{array}$ & $0.2 \pm 0.5$ & $0.4 \pm 0.7^{\mathrm{a}}$ & $0.3 \pm 0.5^{\mathrm{b}}$ \\
$\begin{array}{l}\text { Incorrect medication } \\
\text { Therapeutic drug monitor- } \\
\text { ing }\end{array}$ & $0.0 \pm 0.0$ & $0.0 \pm 0.1$ & $0.0 \pm 0.0$ \\
\hline
\end{tabular}

$S D$ standard deviation

${ }^{\text {a }}$ Statistically significant for comparison between geriatrician and outpatient pharmacist

${ }^{\mathrm{b}}$ Statistically significant for comparison between geriatrician and CDSS

${ }^{\mathrm{c}}$ Statistically significant for comparison between outpatient pharmacist and CDSS 
there were any cognitive or practical barriers. It is important to specify that the geriatrician and outpatient pharmacist did not consult the CDSS for their patients. The information collected on medication review was shared in the patient's file, accessible to all disciplines.

Statistical analysis was performed with IBM SPSS Statistics 23. Paired sampled $T$ test was used to analyse differences in number and type of remarks between the geriatricians, outpatient pharmacist and CDSS. In these comparative analysis the corresponding sample size as mentioned above, was used. The Bonferroni correction was applied to address the problem of multiple comparisons. Continuous variables are reported as means ( \pm standard deviation $(\mathrm{SD})$ ) and categorical variables as percentages.

\section{Results}

In total 200 patients were included of which 118 (59\%) were female. The mean age of the population was $82( \pm 6)$ years. The mean number of medications used was $8( \pm 4)$ including OTC and as required medications. Categorizing medication to ATC code, we see $\geq 40 \%$ of the patients use PPIs, vitamin $\mathrm{D}$, anticoagulants, diuretics, beta blocking agents, agents acting on the renin-aldosterone-angiotensin system (RAAS), and statins ("Appendix 1"). More than $20 \%$ of the patients used drugs for constipation, mineral supplements (mainly calcium), cardiac therapy, analgesics other than opioids and hypnotics (mainly benzodiazepines).

The total number of remarks by the geriatrician was 263 $(\mathrm{n}=200)$ compared with $145(\mathrm{n}=54)$ by the outpatient pharmacist and $945(n=197)$ by the CDSS (809 'green' and 136 'red' reports). The mean number of remarks per patient by the geriatrician was $1.3( \pm 1.5)$, compared with $2.7( \pm 1.4)$ by the outpatient pharmacist and $4.6( \pm 3.6)$ by the CDSS $(p<0.05)$. The outpatient pharmacist thus had twice as much remarks about the same patient than the geriatrician. In addition, the CDSS provides 1.8 times more remarks than the outpatient pharmacist and 3.6 times more than the geriatrician (both $p<0.001$ ).

There are significant differences in the number of categories in which the geriatrician, outpatient pharmacist, and CDSS noted remarks. That is, the CDSS $(1.8 \pm 0.8$ vs. $0.9 \pm 0.9, p<0.001)$ and outpatient pharmacist $(1.8 \pm 0.8$ vs. $0.9 \pm 0.9, p<0.05)$ both noted remarks in more categories than the geriatricians. Regarding the specific categories, the CDSS provided more remarks on 'double medication', 'dosage problem' and 'contraindication/interaction/adverse effects' than the geriatrician did $(p<0.050)$, while the geriatrician provided more remarks on 'medication without indication' than the CDSS did $(p<0.001)$. The number of categories in which the outpatient pharmacist and CDSS noted remarks did not differ significantly $(1.8 \pm 0.8$ vs. $1.8 \pm 0.8$, $p=0.458)$. However, the CDSS did note significantly more remarks in the 'contraindication/interaction/adverse effects' and 'therapeutic drug monitoring' category than the outpatient pharmacist, while the outpatient pharmacist noted more remarks than the CDSS in the 'indication without medication' and 'medication without indication' categories $(p \leq 0.007)$ (Table 1).

The three categories in which geriatricians reported remarks most commonly were 'medication without indication', 'indication without medication', and 'contra-indication/interaction/adverse effect'. Analysis of the content of remarks in the 'indication without medication' category shows that mostly vitamins, analgesics, laxatives, and diuretics in patients with congestive heart failure were reported as missing medication. On the other hand benzodiazepines, betahistin, opiates and antihistamines frequently emerged as 'medication without indication'. In the 'contra-indication/ interaction/adverse effect' category, antihypertensive agents and non-steroidal-anti-inflammatory drugs (NSAIDs) were identified particularly as problem-causing medication.

The most commonly reported remarks by the outpatient pharmacist were on 'indication without medication', 'medication without indication' and 'dosage adjustment'. Adequate pain medication, vitamin $\mathrm{D}$, and calcium supplementation in case of insufficient dairy intake were advised in 'indication without medication'. In contrast to the geriatricians, the largest share of remarks within the 'medication without indication' category concerns PPIs and a smaller share of betahistin and antihistamines. Finally, dosage adjustment is recommended especially for blood-glucoselowering-agents and statins.

Besides remarks in the seven categories, the outpatient pharmacist focused on efficiency of medication prescriptions, drug adherence, use of OTC medications, and presence of a medication organizer or blister pack. These remarks are not included in Table 1. In this study, in 5.6\% of the prescriptions there was a less expensive alternative. Drug adherence was assessed 'well' in $72.2 \%$ of the patients. Just over half (51.9\%) of the patients indicated use of OTC medications (mostly vitamins and analgesics). A medication organizer or blister pack was present in $57.4 \%$ of the patients. The number of medications patients indicated to use, compared to the number in their medication profile, only corresponded in $29.6 \%$.

Most of the CDSS reports are coded 'green' (85.6\%), leaving the remainder 'red' (14.4\%). This implies that most reports do not require prompt action of the physician, but in approximately one out of every seven patients, there are potential hazards. Most CDSS reports were on 'contraindications/interactions/adverse effects' with particular remarks on the use of opiates without laxatives, use of metformin in renal failure and use of tricyclic antidepressant combined with opioids or calcium antagonists. In "indication without 
medication", the majority of reports was on use of PPIs in concomitant use of ASA.

Figure 1 shows in what percentage of patients a certain number of remarks was reported in one of the seven categories (also see "Appendix 2").

\section{Discussion}

\section{Different perspectives in medication review}

This study showed that multiple ways of medication review lead to different perspectives. First, a lower total of remarks was noticed by the geriatrician, compared with the outpatient pharmacist and the CDSS. This probably has to do with the fact that the geriatrician was not specifically instructed to perform a medication review and the outpatient pharmacist was (instruction bias). In addition the geriatrician has limited time to take a patient's history, perform a physical examination, interpret additional diagnostics and discuss a treatment plan. Limited time has previously been mentioned as one of the most important constraints in performing medication reviews [25]. It is questionable whether more reports by the outpatient pharmacist and more CDSS alerts lead to more clinically relevant reports. Despite the lower number of reports from the geriatricians, these all had clinical relevance
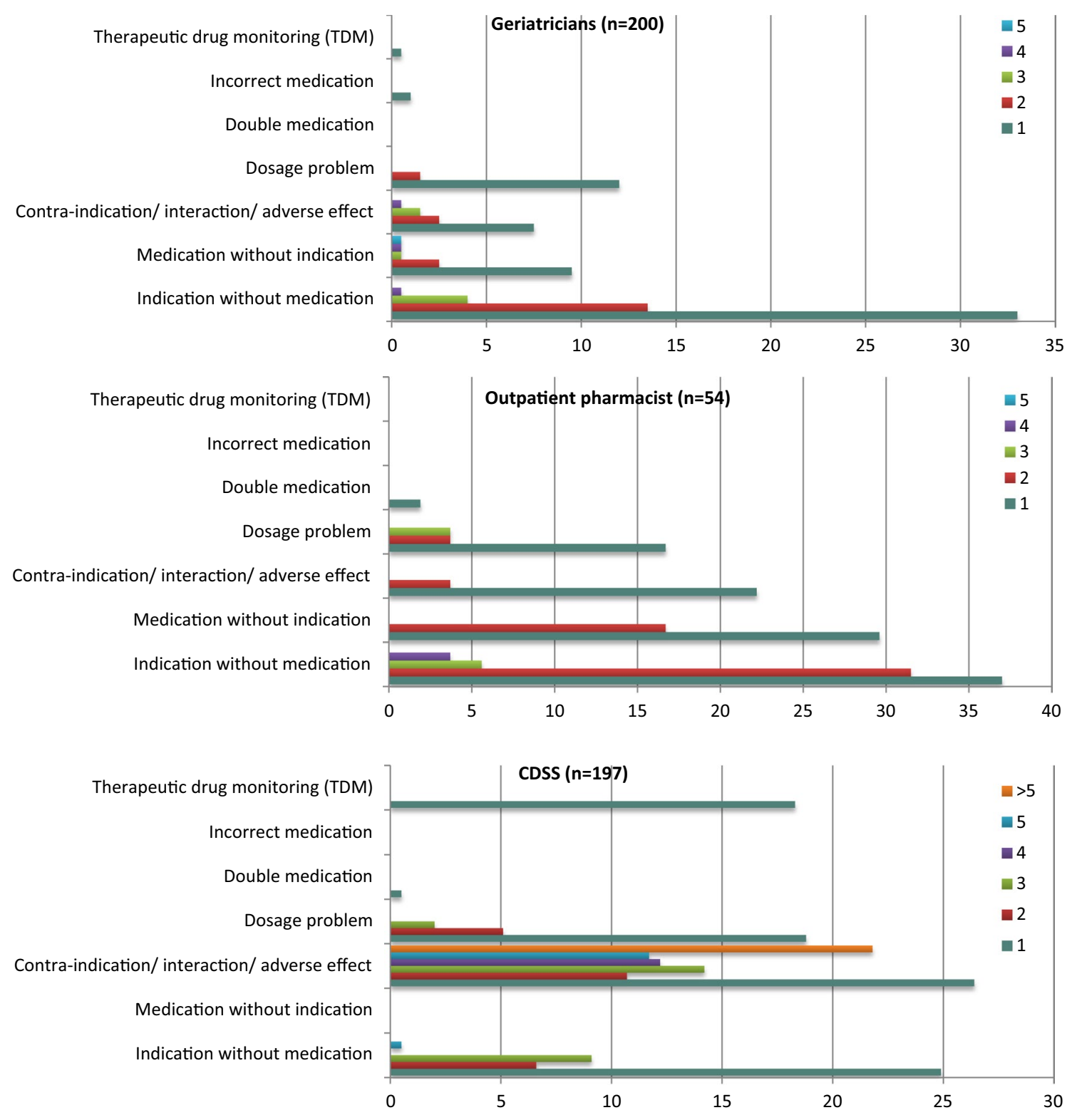

Fig. 1 The number of remarks per category (\% of patients) 
as evaluated by an independent geriatrician. As a consequence of a standardized review guideline, there were no differences in the number of remarks between the geriatricians.

Moreover, the geriatricians mainly focused on 'indication without medication', 'medication without indication' and 'contra-indication/interaction/adverse effect', whilst the outpatient pharmacist focused on these first two and 'dosage problem'. Regarding 'indication without medication' the similarities between the geriatrician and outpatient pharmacist include prescribing adequate pain-medication and vitamin D. The geriatrician focused on specific medical conditions such as congestive heart failure, whereas the outpatient pharmacist did on general problems such as insufficient dairy intake. The differences in nature and scope of the remarks could be explained by educational differences and clinical judgement on a different level by the geriatrician. Overall, all remarks in this category from both the geriatrician and outpatient pharmacist seemed clinically relevant.

Both the geriatricians and outpatient pharmacist considered betahistin and antihistamines as "medication without indication'. This is of particular interest because of the anticholinergic effects and potential adverse events associated with the use of antihistamines [26]. There was however a clear difference between both groups, as the outpatient pharmacist emphasizes that PPIs are used too often. Previous studies have shown that the use of PPIs amongst older patients is high and often inappropriate, and could cause potential harm [27]. Perhaps pharmacists are more aware of this problem, as adding a pharmacist to a medication review team more often causes de-prescribing of PPIs [28, 29]. However, the impact of de-prescribing PPIs on clinical outcomes is still not clear [29]. Lastly, the outpatient pharmacist had more remarks on 'dosage problems', possibly by a greater emphasis on and knowledge of pharmacokinetics.

\section{Pharmacist-provided medication review}

In addition, the outpatient pharmacist provided information on efficiency of medication prescriptions, drug adherence, use of OTC medications, and presence of a medication organizer or blister. From an economic perspective, given the rising health-care costs in the Netherlands [30], it is interesting to discuss less expensive alternatives for medication. In this study, in 5.6\% there was a less expensive alternative, suggesting that there already is emphasis on efficiency when prescribing medication, although it still provides possible cost reduction. Drug adherence was documented as 'well' in $72.2 \%$ of the patients, while just over half $(57.4 \%)$ of the patients used a medication organizer or blister pack. Previous studies documented low drug adherence, particularly in chronic conditions, and adherence in such case is estimated to average 50\% [31-33]. Despite the low number of reliable trials, some studies showed trends to improved adherence whilst using medication organizers or blister packs [34]. Adequate drug adherence is central to successful treatment of underlying diseases as non-adherence could lead to potential harm. This advocates focus on drug adherence during medication review and shows one of the benefits of including a pharmacist in this process. Overall, the pharmacist seems to have an important role in areas of medication safety, efficiency and drug adherence. Although previous literature showed neutral [35] and favourable [20, 36] evidence towards clinical and economical outcomes of pharmacist-provided medication review, we advocate pharmacist-geriatrician collaboration.

\section{Clinical Decision Support System}

Focusing on the CDSS, there is particular potential in reviewing 'contraindications/interactions/adverse effects', as it is a system based on clinical rules. These rules, that include the STOPP/START criteria are useful in identifying PIP [37, 38]. Although most of the CDSS reports did not require prompt action from the physician, there were potential hazards in $14.4 \%$ of the medication profiles. The CDSS could therefore offer concrete and systematic ways of improving (de)prescribing medication and medication safety. Moreover, this set of clinical rules can be updated continuously and provides guidance to physicians working with older patients and polypharmacy. The disadvantage of CDSSs is the absence of clinical judgment and the fact that clinical rules apply at population level but not always on the individual.

\section{Joint medication review}

Overall, there are pros and cons that arise from medication review performed by a geriatrician, outpatient pharmacist and CDSS. Because each reviewer has its qualities and disadvantages, an integrated multidisciplinary approach seems 
most desirable. Regardless of the way of medication review, prior research advocates interprofessional collaboration to achieve better clinical and economic outcomes [39]. One possible approach is using the CDSS in preparation of an outpatient visit and then have a (partly) joint geriatricianpharmacist consultation. Of course, this would require time investment in preparation of consultations and less time for other clinical activities. On the other hand using the CDSS prior to consultations could possibly save time during medication review. Another approach is an outpatient clinic specialized in polypharmacy with joint geriatrician-pharmacist consultation, but this would only be feasible for a limited number of patients. Our future aim is a clear instrument for medication review with the least time investment and the greatest impact on clinical and economic outcomes. So far, to our knowledge, no big randomized trials have been conducted that focus on the effect of medication review in non-hospitalized older patients on long-term clinical and economic outcomes. The potentially beneficial effects of medication review or pharmacological intervention [40, 41] therefore require further research.

\section{Limitations}

First of all, the outpatient pharmacist only reviewed a quarter of all medication profiles due to logistical challenges. Because patients were seen at different locations, it was not feasible for the outpatient pharmacist to be present at both. On the other hand, these patients were selected randomly and all statistical analyses were performed with paired T-tests in an attempt to correct this. Second, the geriatricians were not instructed specifically to perform a medication review and the outpatient pharmacist was. As a result, the number of remarks is not entirely comparable. Finally, this is a descriptive study, so no statements can be made on effects of medication review on clinical or economical outcomes.

\section{Conclusion}

Medication review by geriatricians mainly focuses on clinically relevant problems for which medication should be initiated or discontinued. Evaluation by an outpatient pharmacist provides additional information on efficiency of prescriptions and drug adherence, that could reduce increasing health care costs and improve quality of care. The CDSS identified potential and therefore preventable hazards in $14 \%$ of the medication profiles. Because medication review performed by a geriatrician, outpatient pharmacist, and CDSS provides different insights it should be combined to create a more comprehensive report on medication profiles. However, further research is required to determine the effects on clinical and economic outcomes.

Acknowledgements We would like to thank Bob van de Loo for technical support in using the Clinical Rule Reporter.

Funding Funding or financial support was not applicable.

Conflicts of interest All authors declare that they have no conflicts of interest.

Open Access This article is distributed under the terms of the Creative Commons Attribution 4.0 International License (http://creativeco mmons.org/licenses/by/4.0/), which permits unrestricted use, distribution, and reproduction in any medium, provided you give appropriate credit to the original author(s) and the source, provide a link to the Creative Commons license, and indicate if changes were made.

\section{Appendix 1}

\begin{tabular}{llllll}
\hline $\begin{array}{l}\text { ATC } \\
\text { code }\end{array}$ & $\begin{array}{l}\text { Percent- } \\
\text { age of } \\
\text { patients } \\
\text { using } \\
\text { medica- } \\
\text { tion (\%) }\end{array}$ & $\begin{array}{l}\text { ATC } \\
\text { code }\end{array}$ & $\begin{array}{l}\text { Percent- } \\
\text { age of } \\
\text { patients } \\
\text { using } \\
\text { medica- } \\
\text { tion }(\%)\end{array}$ & $\begin{array}{l}\text { ATC } \\
\text { code }\end{array}$ & $\begin{array}{l}\text { Percentage } \\
\text { of patients } \\
\text { using } \\
\text { medication } \\
(\%)\end{array}$ \\
\hline A02A & 1 & B03B & 12 & M01 & 8 \\
A02B & 59 & B03X & 0.5 & M04 & 6.5 \\
A03 & 2 & C01 & 23.5 & M05 & 13.5 \\
A04 & 1 & C02 & 2.5 & N02A & 18.5 \\
A05 & 0 & C03 & 42 & N02B & 22 \\
A06 & 23.5 & C07 & 41 & N03 & 6.5 \\
A07 & 1 & C08 & 18.5 & N04 & 3.5 \\
A10A & 7.5 & C09 & 48 & N05A & 4.5 \\
A10B & 18.5 & C10 & 44 & N05C & 24.5 \\
A11 & 42 & D & 10.5 & N06A & 18 \\
A12 & 24.5 & G & 13.5 & N06D & 3 \\
B01 & 64 & H & 13.5 & R & 17 \\
B02 & 1 & H02 & 6 & S & 13.5 \\
B03A & 3.5 & J & 2 & OTHER & 11.5 \\
\hline & & & & & \\
\hline
\end{tabular}




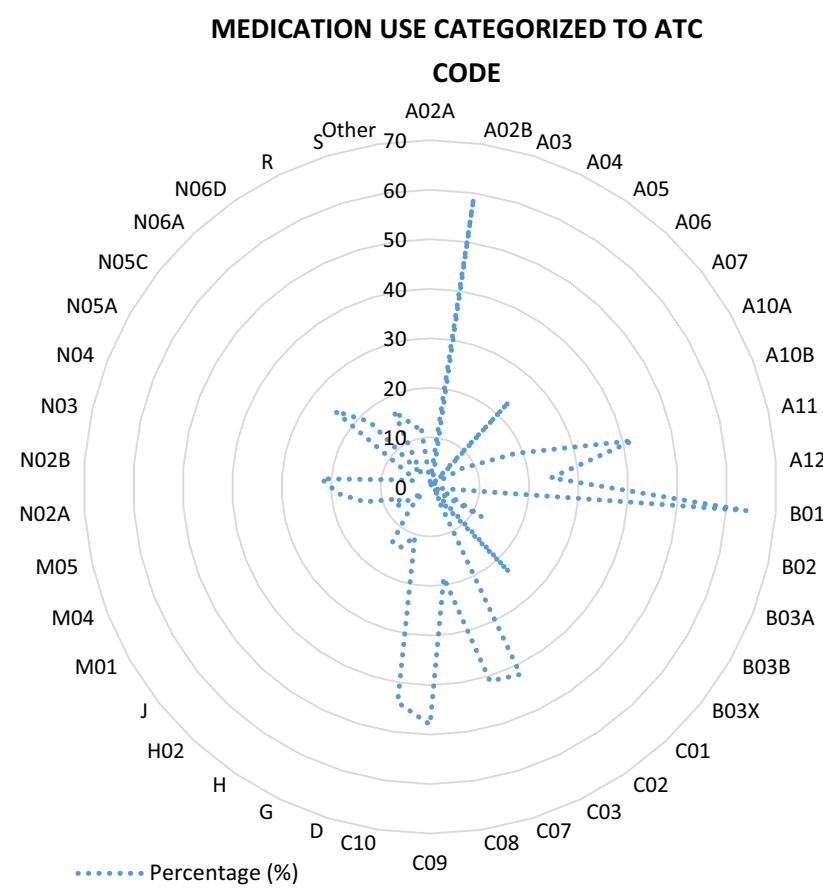

Definition of ATC codes

A02A antacids

A02B drugs for peptic ulcer and gastro-esophageal reflux disease (protonpumpinhibitors, $\mathrm{H} 2$ receptor antagonists)

A03 drugs for functional gastro-intestinal disorders

A04 anti-emetics and anti-nauseants

A05 bile and liver therapy

A06 drugs for constipation

A07 antidiarrheals, intestinal anti-inflammatory/anti-infective agents

A10A insulins and analogues

A10B blood glucose lowering drugs excl. insulins

A11 vitamins

A12 mineral supplements
Definition of ATC codes

B01 antithrombotic agents

B02 antihemorrhagics (e.g. vitamin K)

B03A iron preparations

B03B vitamin B12 and folic acid

B03X other anti-anemic preparations

C01 cardiac therapy

C02 anti-hypertensives

C03 diuretics

$\mathrm{C} 07$ beta blocking agents

C08 calcium channel blockers

C09 agents acting on the renin-angiotensin system

C10 lipid modifying agents

D dermatologicals

G genito-urinary system and sex hormones

$\mathrm{H}$ systemic hormonal preparations, excl. sex hormones and insulins

H02 corticosteroids for systemic use

$\mathrm{J}$ anti-infectives for systemic use

M01 anti-inflammatory and anti-rheumatic products

M04 anti-gout preparations

M05 drugs for treatment of bone disease

N02A opioids

N02B other analgesics and antipyretics

N03 anti-epileptics

N04 anti-Parkinson drugs

N05A antipsychotics

N05C hypnotics and sedatives

N06A antidepressants

N06D anti-dementia drugs

$\mathrm{R}$ respiratory system

$\mathrm{S}$ sensory organs 


\section{Appendix 2}

Categories of remarks

\begin{tabular}{|c|c|c|c|c|c|c|c|}
\hline \multirow{2}{*}{$\begin{array}{l}\text { No. of } \\
\text { remarks }\end{array}$} & \multicolumn{7}{|l|}{ Category } \\
\hline & $\begin{array}{l}\text { Indication with- } \\
\text { out medication }\end{array}$ & $\begin{array}{l}\text { Medication with- } \\
\text { out indication }\end{array}$ & $\begin{array}{l}\text { Contra-indica- } \\
\text { tion/interaction/ } \\
\text { side-effect }\end{array}$ & Dosage problem & $\begin{array}{l}\text { Double medica- } \\
\text { tion }\end{array}$ & $\begin{array}{l}\text { Incorrect medi- } \\
\text { cation }\end{array}$ & $\begin{array}{l}\text { Therapeutic } \\
\text { drug monitor- } \\
\text { ing (TDM) }\end{array}$ \\
\hline \multicolumn{8}{|c|}{ Geriatrician $(n=200)$} \\
\hline 0 & $98(49 \%)$ & $173(86.5 \%)$ & $176(88 \%)$ & $173(86.5 \%)$ & $200(100 \%)$ & $198(99 \%)$ & $199(99.5 \%)$ \\
\hline 1 & $66(33 \%)$ & $19(9.5 \%)$ & $15(7.5 \%)$ & $24(12 \%)$ & - & $2(1 \%)$ & $1(0.5 \%)$ \\
\hline 2 & $27(13.5 \%)$ & $5(2.5 \%)$ & $5(2.5 \%)$ & $3(1.5 \%)$ & - & - & - \\
\hline 3 & $8(4 \%)$ & $1(0.5 \%)$ & $3(1.5 \%)$ & - & - & - & - \\
\hline 4 & $1(0.5 \%)$ & $1(0.5 \%)$ & $1(0.5 \%)$ & - & - & - & - \\
\hline 5 & - & $1(0.5 \%)$ & - & - & - & - & - \\
\hline \multicolumn{8}{|c|}{ Outpatient pharmacist $(\mathrm{n}=54)$} \\
\hline 0 & $12(22.2 \%)$ & $29(53.75 \%)$ & $40(74.1 \%)$ & $41(75.9 \%)$ & $53(98.1 \%)$ & $54(100 \%)$ & $54(100 \%)$ \\
\hline 1 & $20(37 \%)$ & $16(29.6 \%)$ & $12(22.2 \%)$ & $9(16.7 \%)$ & $1(1.9 \%)$ & - & - \\
\hline 2 & $17(31.5 \%)$ & $9(16.7 \%)$ & $2(3.7 \%)$ & $2(3.7 \%)$ & - & - & - \\
\hline 3 & $3(5.6 \%)$ & - & - & $2(3.7 \%)$ & - & - & - \\
\hline 4 & $2(3.7 \%)$ & - & - & - & - & - & - \\
\hline 5 & - & - & - & - & - & - & - \\
\hline \multicolumn{8}{|c|}{$\operatorname{CDSS}(n=197)$} \\
\hline 0 & $116(58.9 \%)$ & $197(100 \%)$ & $6(3 \%)$ & $146(74.1 \%)$ & $196(99.5 \%)$ & $197(100 \%)$ & $161(81.7 \%)$ \\
\hline 1 & $49(24.9 \%)$ & - & $52(26.4 \%)$ & $37(18.8 \%)$ & $1(0.5 \%)$ & - & $36(18.3 \%)$ \\
\hline 2 & $13(6.6 \%)$ & - & $21(10.7 \%)$ & $10(5.1 \%)$ & - & - & - \\
\hline 3 & $18(9.1 \%)$ & - & $28(14.2 \%)$ & $4(2 \%)$ & - & - & - \\
\hline 4 & - & - & $24(12.2 \%)$ & - & - & - & - \\
\hline 5 & $1(0.5 \%)$ & - & $23(11.7 \%)$ & - & - & - & - \\
\hline$\geq 5$ & - & - & $43(21.8 \%)$ & - & - & - & - \\
\hline
\end{tabular}

\section{References}

1. Gruneir A, Silver M, Rochon PA. Emergency department use by older adults: a literature review on trends, appropriateness, and consequences of unmet health care needs. Med Care Res Rev. 2011;68:131-55.

2. Huang JA, Weng RH, Tsai WC, Hu WH, Yang DY. Analysis of emergency department utilization by elderly patients under National Health Insurance. Kaohsiung J Med Sci. 2003;19(3):113-20.

3. Roberts DC, McKay MP, Shaffer A. Increasing rates of emergency department visits for elderly patients in the United States, 1993 to 2003. Ann Emerg Med. 2008;51(6):769-74.

4. Salvi F, Morichi V, Grilli A, Giorgi R, De Tommaso G, Dessi-Fulgheri $P$. The elderly in the emergency department: a critical review of problems and solutions. Intern Emerg Med. 2007;2(4):292-301.

5. Strange GR, Chen E. Use of emergency departments by elder patients: a five-year follow-up study. Acad Emerg Med. 1998;5:1157-63.

6. Buurman BM, Hoogerduijn JG, de Haan RJ, Abu-Hanna A, Lagaay AM, Verhaar HJ, et al. Geriatric conditions in acutely hospitalized older patients: prevalence and one-year survival and functional decline. PLoS One. 2011;6(11):e26951.
7. Fried LP, Tangen CM, Walston J, Newman AB, Hirsch C, Gottdiener J. Frailty in older adults: evidence for a phenotype. J Gerontol A Biol Sci Med Sci. 2001;56(3):M146-56.

8. McCusker J, Bellavance F, Cardin S, Trepanier S. Screening for geriatric problems in the emergency department: reliability and validity. Identification of Seniors at Risk (ISAR) Steering Committee. Acad Emerg Med. 1998;5(9):883-93.

9. Hohl CM, Dankoff J, Colacone A, Afilalo M. Polypharmacy, adverse drug-related events, and potential adverse drug interactions in elderly patients presenting to an emergency department. Ann Emerg Med. 2001;38(6):666-71.

10. Leape LL, Brennan TA, Laird N, Lawthers AG, Localio AR, Barnes BA et al. The nature of adverse events in hospitalized patients. Results of the Harvard Medical Practice Study II. N Engl J Med. 1991;324(6):377-84.

11. Griese-Mammen N, Hersberger KE, Messerli M, Leikola S, Horvat N, van Mil JWF, et al. PCNE definition of medication review: reaching agreement. Int J Clin Pharm. 2018;40(5):1199-208.

12. Dutch General Practitioners Association (NHG). D.A.f.C.G.N., order of medical specialists (OMS), multidisciplinary guideline polypharmacy in the elderly. Utrecht: NHG; 2012.

13. Barry PJ, Gallagher P, Ryan C, O'Mahony D. START (screening tool to alert doctors to the right treatment) — an evidence-based 
screening tool to detect prescribing omissions in elderly patients. Age Ageing. 2007;36(6):632-8.

14. Gallagher P, Ryan C, Byrne S, Kennedy J, O'Mahony D. STOPP (Screening Tool of Older Person's Prescriptions) and START (Screening Tool to Alert doctors to Right Treatment). Consensus validation. Int J Clin Pharmacol Ther. 2008;46(2):72-83.

15. Gallagher PF, O'Connor MN, O'Mahony D. Prevention of potentially inappropriate prescribing for elderly patients: a randomized controlled trial using STOPP/START criteria. Clin Pharmacol Ther. 2011;89(6):845-54.

16. Patterson SM, Cadogan CA, Kerse N, Cardwell CR, Bradley $\mathrm{MC}$, Ryan $\mathrm{C}$ et al. Interventions to improve the appropriate use of polypharmacy for older people. Cochrane Database Syst Rev. 2014;10:CD008165.

17. Ammenwerth E, Schnell-Inderst P, Machan C, Siebert U. The effect of electronic prescribing on medication errors and adverse drug events: a systematic review. J Am Med Inform Assoc. 2008;15(5):585-600.

18. Jia P, Zhang L, Chen J, Zhao P, Zhang M. The effects of clinical decision support systems on medication safety: an overview. PLoS One. 2016;11(12):e0167683.

19. Kaushal R, Shojania KG, Bates DW. Effects of computerized physician order entry and clinical decision support systems on medication safety: a systematic review. Arch Intern Med. 2003;163(12):1409-16.

20. Chisholm-Burns MA, Kim Lee J, Spivey CA, Slack M, Herrier RN, Hall-Lipsy E et al. US pharmacists' effect as team members on patient care: systematic review and meta-analyses. Med Care. 2010;48(10):923-33.

21. Riordan DO, Walsh KA, Galvin R, Sinnott C, Kearney PM, Byrne $\mathrm{S}$. The effect of pharmacist-led interventions in optimising prescribing in older adults in primary care: a systematic review. SAGE Open Med. 2016;4:2050312116652568.

22. Central Statistics Office. People over 65 per municipality in the Netherlands. 2013.

23. WHO. Guidelines for ATC classification and DDD assignment 2013. 2013.

24. Hurkens KP, Mestres-Gonzalvo C, Wit H, De Janknegt R, Verhey $\mathrm{F}$, Schols J, et al. Assessing the strengths and weaknesses of a computer assisted medication review in hospitalized patients. Int J Hosp Pharm. 2017;2(6):1-12.

25. Anderson K, Stowasser D, Freeman C, Scott I. Prescriber barriers and enablers to minimising potentially inappropriate medications in adults: a systematic review and thematic synthesis. BMJ Open. 2014;4(12):e006544.

26. Ablett AD, Wood AD, Barr R, Guillot J, Black AJ, Macdonald $\mathrm{HM}$ et al. A high anticholinergic burden is associated with a history of falls in the previous year in middle-aged women: findings from the Aberdeen Prospective Osteoporosis Screening Study. Ann Epidemiol. 2018;28(8):557-562.

27. Heidelbaugh JJ, Goldberg KL, Inadomi JM. Overutilization of proton pump inhibitors: a review of cost-effectiveness and risk [corrected]. Am J Gastroenterol. 2009;104(Suppl 2):S27-32.

28. Farrell B, Pottie K, Thompson W, Boghossian T, Pizzola L, Rashid FJ et al. Deprescribing proton pump inhibitors: evidence-based clinical practice guideline. Can Fam Physician. 2017;63(5):354-64.

29. Wilsdon TD, Hendrix I, Thynne TR, Mangoni AA. Effectiveness of interventions to deprescribe inappropriate proton pump inhibitors in older adults. Drugs Aging. 2017;34(4):265-87.

30. Central Statistical Office. Health care expenses: key figures. 2017 The Netherlands. Via: https://opendata.cbs.nl/\#/CBS/nl/datas et/84047NED/table?ts=1547042128792. Accessed 10 July 2019.

31. World Health Organisation (WHO). Adherence to long-term therapies. Evidence for action. 2003. Via: https://www.who.int/ chp/knowledge/publications/adherence_full_report.pdf?ua $=1$. Accessed 10 July 2019.

32. Benner JS, Glynn RJ, Mogun H, Neumann PJ, Weinstein MC, Avorn J. Long-term persistence in use of statin therapy in elderly patients. JAMA. 2002;288(4):455-61.

33. Morrison A, Wertheimer A, Berger M. Interventions to improve antihypertensive drug adherence: a quantitative review of trials. Formulary. 2000;35:234-55.

34. Connor J, Rafter N, Rodgers A. Do fixed-dose combination pills or unit-of-use packaging improve adherence? A systematic review. Bull World Health Organ. 2004;82(12):935-9.

35. Loh ZW, Cheen MH, Wee HL. Humanistic and economic outcomes of pharmacist-provided medication review in the community-dwelling elderly: a systematic review and meta-analysis. J Clin Pharm Ther. 2016;41(6):621-33.

36. Klopotowska JE, Kuiper R, van Kan HJ, de Pont AC, Dijkgraaf MG, Lie A et al. On-ward participation of a hospital pharmacist in a Dutch intensive care unit reduces prescribing errors and related patient harm: an intervention study. Crit Care. 2010;14(5):R174.

37. Hill-Taylor B, Sketris I, Hayden J, Byrne S, O’Sullivan D, Christie R. Application of the STOPP/START criteria: a systematic review of the prevalence of potentially inappropriate prescribing in older adults, and evidence of clinical, humanistic and economic impact. J Clin Pharm Ther. 2013;38(5):360-72.

38. Hill-Taylor B, Walsh KA, Stewart S, Hayden J, Byrne S, Sketris IS. Effectiveness of the STOPP/START (Screening Tool of Older Persons' potentially inappropriate Prescriptions/Screening Tool to Alert doctors to the Right Treatment) criteria: systematic review and meta-analysis of randomized controlled studies. J Clin Pharm Ther. 2016;41(2):158-69.

39. Silva ROS, Macedo LA, Santos GAD Jr, Aguiar PM, de Lyra DP Jr. Pharmacist-participated medication review in different practice settings: service or intervention? An overview of systematic reviews. PLoS One. 2019;14(1):e0210312.

40. Christensen M, Lundh A. Medication review in hospitalised patients to reduce morbidity and mortality. Cochrane Database Syst Rev. 2016. https://doi.org/10.1002/14651858.CD008986. pub3.

41. Ros JJW, Koekkoek TJ, Kalf A, van den Bemt PMLA, Van Kan HJM. Impact of joint consultation by a clinical pharmacist and a clinical geriatrician to improve inappropriate prescribing for elderly patients. Eur J Hosp Pharm. 2017;24:26-30.

Publisher's Note Springer Nature remains neutral with regard to jurisdictional claims in published maps and institutional affiliations. 